\title{
Use of Intravitreal Triamcinolone in the Treatment of Macular Edema Related to Retinal Vein Occlusion
}

\author{
Ashish Sharma, Baruch D. Kuppermann and M. Cristina Kenney ${ }^{*}$
}

Department of Ophthalmology, School of Medicine, University of California, Irvine, USA

\begin{abstract}
Objective: To analyze the increasing trend of intravitreal triamcinolone (IVTA) use in the treatment of retinal vein occlusion-related macular edema. Methods: We performed MEDLINE/PUBMED searches (September 1984 - December 2007) to identify articles containing the keywords macular edema and triamcinolone. Case reports, reviews and abstracts were identified from references in the reviewed literature. This review focuses on literature published during the past 7 years with more than two-thirds of the articles that we reviewed being printed during the past 5 years. These reports analyzed the success of IVTA in the treatment of macular edema over a 12 month course of time. Results: The majority of studies suggested promising results for short time periods (4-6 months) after IVTA treatments. However, long term results were not encouraging. Conclusions: The success of IVTA therapy for short durations has been the impetus for development of sustained release devices to be used in the treatment of macular edema associated with various retinal diseases including edema related to retinal vein occlusion.
\end{abstract}

Keywords: Intravitreal triamcinolone, macular edema, retinal vein occlusion.

\section{INTRODUCTION}

Retinal vein occlusion (RVO) is second only to diabetic retinopathy as the most common form of retinal vascular disease in the United States [1]. The cumulative 10-year incidence of retinal vein occlusion was estimated to be $1.6 \%$ in the Blue Mountains population study of individuals aged 49 years and older [2].

Although the pathophysiology of RVO is poorly understood, an important final common pathway is retinal ischemia. Some of the major pathological effects of ischemia on tissue includes breakdown of inner blood-retinal barrier [3], increased VEGF production [4] and generalized inflammation of retinal tissue by release of prostaglandin and interleukins [5].

The clinical course of central retinal vein occlusion (CRVO) and branch retinal vein occlusion (BRVO) may differ but a major cause of visual loss is macular edema in both the diseases [6]. Other causes of visual loss are ischemia and the presence of central hemorrhage.

Therapies in RVO have two aims. One is to reduce macular edema and the other is to prevent neovascularization caused by retinal ischemia. Many therapies such as laser photocoagulation, anticoagulation, hemodilution, laserinduced chorioretinal anastomosis, anti-VEGF treatment, vitrectomy, sheathotomy, and intravitreal steroids have been used to treat these complications [6].

Among these treatments, only anti-VEGF medications, laser photocoagulation, and intravitreal steroids address the pathophysiological mechanisms responsible for vein occlusion. Anti-VEGF medications (Ranibizumab and Bevacizumab) have excellent effects except in cases of severely ischemic retina. Laser photocoagulation improves visual

*Address correspondence to this author at the Department of Ophthalmology, School of Medicine, University of California, Irvine, USA;

E-mail: mkenney@uci.edu acuity (VA) in patients with BRVO associated macular edema but is ineffective in improving VA in patients with macular edema associated with CRVO [7]. Overall, laser treatment of perfused macular edema only minimally improves vision and offers little hope for patients with poor pretreatment visual acuity. The benefits for ischemic macular edemas are still not known.

Reports have suggested a role for surgical interventions in the treatment of retinal vein occlusion but results of randomized clinical trials are not favorable [8-10].

Being a less traumatic option of treatment, intravitreal steroids are gaining popularity. At this time intravitreal triamcinolone (IVTA) is the most frequently used steroid. Small case series confirmed the visual benefit of IVTA in both perfused and ischemic macular edema. Studies have revealed that it reduces macular edema in both CRVO and BRVO [10, 11]. Greater effects were observed on nonischemic CRVO than ischemic CRVO [12].

There are some complications of IVTA such as increased intraocular pressure (IOP), cataract formation [13], and sterile endophthalmitis [14]. A major limiting factor of intravitreal steroids is their short duration of action. Many studies revealed that effects of IVTA treatment persist for only 4-6 months [15].

\section{RESULTS}

\section{Best Corrected Visual Acuity}

Three of four studies showed improved best corrected visual acuity (BCVA) for approximately 3 months after IVTA injection but there was a subsequent decline in the vision at 1 year. Table 1 shows the BCVA at follow up visits of 1,3 and 12 months.

\section{Central Foveal Thickness}

Significant improvement in the central foveal thickness was reported in macular edema due both to BRVO and 
Table 1. Summary of Improvement of Best Corrected Visual Acuity After IVTA Injections

\begin{tabular}{|c|c|c|c|c|}
\hline Baseline BCVA & 1 Month After IVTA & 3 Months After IVTA & 12 Months After IVTA & Ref \\
\hline $20 / 400$ & $20 / 300$ & $20 / 300$ & $8 / 200$ & {$[16]$} \\
\hline $20 / 100$ & $20 / 50$ & $20 / 50$ & $20 / 70$ & {$[17]$} \\
\hline $20 / 300$ & $20 / 166$ & $20 / 130$ & $20 / 270$ & {$[18]$} \\
\hline worse than $20 / 50$ & better than $20 / 50$ & better than $20 / 50$ & better than $20 / 40$ & {$[19]$} \\
\hline
\end{tabular}

CRVO after IVTA injections [16-18, 20-24]. Table 2 shows that the central foveal thickness as measured by optical coherence tomography (OCT) dramatically decreases through the $3^{\text {rd }}$ month post treatment. However at the 6 month visit there is no significant difference from the baseline thickness and in most of the studies the macular edema had returned.

\section{Need to Repeat Injection}

Most of the studies showed that IVTA injections needed to be repeated between the $4^{\text {th }}$ and $12^{\text {th }}$ months during the follow up period [16-18].

\section{Complications}

In the published literature, the most common complication of IVTA treatment was a transient rise in IOP, and was controlled with topical medication [26-31]. Wingate and coworkers reported that approximately $30 \%$ of the study group develop a significant rise $(\geq 5 \mathrm{~mm} \mathrm{Hg})$ in IOP above baseline during the first 3 months [30]. Other reported complications were cataract progression and pseudohypopyon [27, 31, 32]. Progression of nuclear sclerotic cataract was reported in $22 \%$ of an older group following a single injection [27]. In the nine published reports of IVTA, a total of 224 eyes in 224 patients have been treated without any reported complication of endophthalmitis [26-31, 33, 34].

\section{DISCUSSION}

The natural history outcome of RVO is very poor [35, 36]. Macular edema associated RVO has always been a difficult condition to treat. Until recently there has been no proven treatment of this pathology. The Central Vein Occlusion Study Group showed that there was no significant difference found in VA between laser-treated and untreated eyes at any follow up time points [35].

There are several case reports showing short-term reduction in macular edema due to CRVO and BRVO as measured by OCT following IVTA $[11,23,37,38]$. Jonas et al. reported significant improvement in VA in both eyes after injection with $25 \mathrm{mg}$ of IVTA in a patient with macular edema due to CRVO [39]. They found decreased fluorescein leakage and did not find any significant complications except mild cataract progression and transient increase in IOP. Park et al. reported significant anatomical and functional improvement in 10 eyes with macular edema due to nonischemic CRVO. In their study of $4 \mathrm{mg}$ IVTA injections and an average follow up of 4.8 months, they found that $60 \%$ of the eyes gained $\geq 2$ lines of VA [23].

Greenberg et al. [34] studied a patient with bilateral macular edema associated with CRVO. After an intravitreal injection of $4 \mathrm{mg}$ TA, there was significant improvement in the acute CRVO eye but no improvement in VA in the eye with chronic CRVO. A second injection was performed due to decline in the VA after 6 months. OCT showed a decrease of macular edema with restoration of normal macular anatomy in both eyes. Fortunately, there was no elevation of IOP in this patient.

Bashshur [40] studied VA changes in 40 eyes with macular edema due to nonischemic CRVO. Twenty eyes were treated by a single intravitreal injection of $4 \mathrm{mg}$ of TA, and the rest were only observed for the natural course of the disease. Baseline BCVA was from 20/50 to 20/200. Over 10 months, $12(60 \%)$ of the 20 treated eyes had a final visual acuity of $20 / 40$ or better, while only $4(20 \%)$ of the 20 eyes in the observation group had a final visual acuity of $20 / 40$ or better.

Ip \& Kumar [37] injected $4 \mathrm{mg}$ IVTA in two patients with macular edema from CRVO and observed an improvement in BCVA in both cases. In one case, concerning a patient with nonischemic CRVO, the improvement lasted until the 6 month follow up visit. In the other case, involving ischemic CRVO, the effect did not last and BCVA after 3 months was worse than before the injection.

Chen and associates $[25,41]$ reported a favorable response to IVTA in a patient with ischemic macular edema associated with BRVO while the study by Jonas and coworkers revealed no improvement in ischemic macular edema in their 2 patients. In their prospective comparative nonrandomized study [42], Jonas treated 10 eyes with $20 \mathrm{mg}$

Table 2. Summary of Central Foveal Thickness After IVTA Injections

\begin{tabular}{|c|c|c|c|c|}
\hline Baseline Central Foveal Thickness & 1 Month After IVTA & 3 Months After IVTA & 6 Months After IVTA & Ref. \\
\hline $590 \mu \mathrm{m}$ & $212 \mu \mathrm{m}$ & $193 \mu \mathrm{m}$ & $281 \mu \mathrm{m}$ & [12] \\
\hline $468 \mu \mathrm{m}$ & $310 \mu \mathrm{m}$ & $311 \mu \mathrm{m}$ & $365 \mu \mathrm{m}$ & {$[20]$} \\
\hline $476 \mu \mathrm{m}$ & $329 \mu \mathrm{m}$ & $389 \mu \mathrm{m}$ & $498 \mu \mathrm{m}$ & {$[21]$} \\
\hline
\end{tabular}

$\mu \mathrm{m}=$ micron. 
to $25 \mathrm{mg}$ IVTA for macular edema associated with BRVO. Their study revealed significant improvement in VA at one month post injection but the long term effect was not reported. Other studies revealed a decline in the BCVA after initial improvement [23, 34, 43, 44].

The most likely cause of the short duration of action of IVTA is elimination of the drug by diffusion. Following intravitreal injection of $4 \mathrm{mg}$, measurable levels of TA have been detected in aqueous humor up to 3 months [15]. In addition, triamcinolone has been found in aqueous up to 1.5 years following single injections of 20 to $25 \mathrm{mg}$ [45].

\section{SUMMARY AND FUTURE}

IVTA is frequently used for the treatment of various intraocular neovascular and edematous conditions such as RVO and diabetic retinopathy. Typically, steroids are administered intravitreally because steroids given as drops, systemically, or injected into the subconjunctival and subTenon's space do not reach high enough concentrations to be effective. Additionally, corticosteroids used systemically for prolonged periods of time increased the risk for systemic side effects.

Studies demonstrated the efficacy of IVTA in reducing macular edema in both CRVO [23, 34] and BRVO [11, 38, 41]. In a majority of these reports, there is a short-term effect of improved retinal thickness, decreased exudation and improved visual acuity, but long-term results were not favorable. It is probable that patients with an initial improvement but subsequent decline in BCVA after IVTA may benefit from repeated treatments but re-injections always involve increased risks and frequent follow up. Steroid implants would perhaps obviate this by providing the edematous macula a lower but steady dose of steroid. At the present time there are ongoing clinical trials to assess the efficacy of intravitreal steroid implants.

The only FDA approved steroid implant Retisert (Bausch \& Lomb, Rochester, NY) contains fluocinolone acetonide within a tiny drug reservoir $(0.59 \mathrm{mg})$ which delivers sustained levels into the vitreous cavity and is sutured to the sclera through a trans-pars plana incision. In 2005, the FDA approved the Retisert implant for the treatment of chronic noninfectious uveitis affecting the posterior segment of the eye [46]. This implant releases drug at an initial rate of 0.6 $\mu \mathrm{g}$ per day, with dosage decreasing after the first month to a steady rate of $0.3 \mu \mathrm{g}$ to $0.4 \mu \mathrm{g}$ per day for approximately 30 months. The most common serious adverse events in the implanted eyes were cataract development requiring extraction and IOP increase. Ninety-five percent of phakic implanted eyes needed cataract surgery, and $35 \%$ of implanted eyes experienced increased IOP. A filtering procedure was needed in $28 \%$ of implanted eyes, and explantation of the insert was done in $5 \%$ of eyes to manage IOP. This fluocinolone acetonide implant also has been studied in a multicenter, randomized, controlled clinical trial for the treatment of diabetic macular edema (DME). Patients were randomized 2:1 to receive either a $0.59 \mathrm{mg}$ fluocinolone acetonide implant or standard of care, which were either repeat laser treatments or observation.

The Medidur implant (Alimera Sciences, Alpharetta GA) also contains fluocinolone acetonide but is much smaller than the Retisert implant. Although the Medidur is a reser- voir implant, it is injected into the vitreous cavity with a 25 gauge syringe and is not sutured to the eye wall, therefore, it is allowed to float freely in the vitreous space. Medidur has two models; one is designed to last approximately 3 years and other lasts approximately 18 months. Enrollment in the phase 3 FAME (Fluocinolone Acetonide in Diabetic Macular Edema) trial, which is evaluating a daily dose of $0.2 \mu \mathrm{g}$ and $0.5 \mu \mathrm{g}$ of fluocinolone acetonide to the retina, has been completed. FAME is a double-masked, randomized, multicenter study involving more than 900 patients in the United States, Canada, Europe and India. Safety and efficacy will be assessed at 2 years, and patients will be followed for 3 years. Results from this trial will help to determine if Medidur FA is effective and capable of reducing the steroid induced side effects seen in the Retisert trial.

There is also recent interest in the Posurdex drug delivery system (Allergan, Inc., Irvine, CA) which is a sustained delivery formulation of dexamethasone. The Posurdex implant is biodegradable, unlike the Retisert and Medidur implants, and undergoes hydrolysis with degradation to lactic acid and glycolic acid, two naturally occurring metabolic by-products that are then further broken down to water and carbon dioxide. The implant is inserted into the vitreous cavity and floats freely in the vitreous base. Two different dexamethasone dose implants were evaluated in a 6 month, Phase 2, multicenter, randomized clinical trial [47].

The 315 patients in the Posurdex trial had persistent macular edema due to either diabetic retinopathy $(n=172)$, RVO $(n=102)$, Irvine-Gass syndrome $(n=27)$ or uveitis $(n=14)$. In each patient, 1 eye was randomized to treatment with either a $350 \mu \mathrm{g}$ dose of Posurdex, or a $700 \mu \mathrm{g}$ dose of Posurdex. At the primary endpoint (day 90 of the study), $2 \%$ of the patients who were implanted with the $350 \mu \mathrm{g}$ dose of Posurdex had an increase in IOP of $10 \mathrm{~mm} \mathrm{Hg}$ or more from baseline, compared with $2 \%$ of patients in the $700 \mu \mathrm{g}$ group and $1 \%$ of patients in the observation arm. All were managed with either observation or topical IOP-lowering medication. No patient required any surgical intervention to control IOP. Cataracts were present in $15 \%$ of the $350-\mu$ g group, $17.8 \%$ of the $700 \mu \mathrm{g}$ group and $12.4 \%$ of the observation group $(\mathrm{P}<0.001$ vs observation). The efficacy results showed a dose response curve that was observed for all subsets of patients based on the underlying cause of macular edema. Overall, $18.1 \%$ of eyes in the $700 \mu \mathrm{g}$ group showed a three line improvement in BCVA at 180 days compared to $7.6 \%$ in the observation group and $14.6 \%$ in the $350 \mu$ group. Clinically and statistically significant reductions in macular thickness by OCT and leakage by fluorescein angiogram were also observed in a dose response fashion. Phase 3 trials are underway evaluating the Posurdex implant for patients with either DME or macular edema caused by RVO.

The prospective, randomized, double-masked STRIDE (Sustained Triamcinolone Release for Inhibition of Diabetic Macular Edema) trial assesses the safety and tolerability of the I-vation TA (SurModics, Eden Prairie, MN) in 30 patients. Dugel and colleagues reported results of a 6 month interim analysis. In the study, patients were randomized to either a slow-release or fast-release implant containing 925 $\mu \mathrm{g}$ of TA. At 6 months, the proportion of patients with BCVA of at least 70 ETDRS letters increased from $14 \%$ to $46 \%$ in the slow-release group and from $18 \%$ to $41 \%$ in the 
fast-release group. $8 \%$ of patients in the slow-release group and $18 \%$ in the fast-release group gained more than 15 letters. Macular thickness improvement was reported with the use of both implants. Mean IOP increased from $13.9 \mathrm{~mm} \mathrm{Hg}$ to $16.1 \mathrm{~mm} \mathrm{Hg}$ in the slow group and from $14.3 \mathrm{~mm} \mathrm{Hg}$ to $16.4 \mathrm{~mm} \mathrm{Hg}$ in the fast group at 6 months. The patients in the STRIDE study will be followed for 3 years.

The National Eye Institute sponsored study called the Standard Care vs COrticosteroid for REtinal Vein Occlusion (SCORE) trial is a multicenter, randomized, Phase III trial to compare the effectiveness and safety of standard care versus IVTA injection(s) for the treatment of macular edema associated with CRVO and BRVO. As of February 29, 2008 when enrollment was concluded, a total 682 subjects with CRVO (271) or BRVO (411) had been randomized in a 1:1:1 ratio to one of three groups: standard care, IVTA $4 \mathrm{mg}$, or IVTA $1 \mathrm{mg}$. Follow up examinations are every 4 months for 3 years and will collect ophthalmic data, including VA, IOP, OCT and fundus photography. Fluorescein angiography will be performed at 4, 12 and 24 months. Based on protocolspecific guidelines, repeat intravitreal injections of TA and repeat laser treatment will be provided as clinically indicated. The primary outcome is improvement by 15 or more letters from baseline in best-corrected ETDRS visual acuity score at the 12 month visit. Secondary outcomes include changes from baseline in best-corrected ETDRS visual acuity score, changes in retinal thickness as assessed by stereoscopic color fundus photography and OCT and adverse ocular outcomes.

Results of the SCORE trial will provide answers regarding the use of IVTA in both CRVO and BRVO.

\section{ACKNOWLEDGEMENTS}

Discovery Eye Foundation, Iris and B. Gerald Cantor Foundation, Gilbert Foundation, Ko Family Foundation, Research to Prevent Blindness Foundation and Henry L. Guenther Foundation.

\section{REFERENCES}

[1] The Branch Vein Occlusion Study Group. Argon laser photocoagulation for macular edema in branch vein occlusion. Am J Ophthalmol 1984; 98: 271-82.

[2] Cugati S, Wang JJ, Rochtchina E, Mitchell P. Ten-year incidence of retinal vein occlusion in an older population: the Blue Mountains Eye Study. Arch Ophthalmol 2006; 124: 726-32.

[3] Wilson CA, Berkowitz BA, Sato Y, Ando N, Handa JT, de Juan E Jr. Treatment with intravitreal steroid reduces blood-retinal barrier breakdown due to retinal photocoagulation. Arch Ophthalmol 1992; 110: 1155-9.

[4] Pe'er J, Folberg R, Itin A, Gnessin H, Hemo I, Keshet E. Vascular endothelial growth factor upregulation in human central retinal vein occlusion. Ophthalmology 1998; 105: 412-6.

[5] Funatsu H, Yamashita H, Noma H, Mimura T, Yamashita T, Hori $\mathrm{S}$. Increased levels of vascular endothelial growth factor and interleukin- 6 in the aqueous humor of diabetics with macular edema. Am J Ophthalmol 2002; 133: 70-7.

[6] Margolis R, Singh R P, Kaiser P K. Branch retinal vein occlusion: Clinical findings, natural history, and management. Compr Ophthalmol Update 2006; 7: 265-76.

[7] Finkelstein D. Argon laser photocoagulation for macular edema in branch vein occlusion. Ophthalmology 1986; 93: 975-7.

[8] Kumagai K, Furukawa M, Ogino N, Uemura A, Larson E. Longterm outcomes of vitrectomy with or without arteriovenous sheathotomy in branch retinal vein occlusion. Retina 2007; 27: 4954.
[9] Furukawa M, Kumagai K, Ogino N, Uemura A, Larson E. Longterm visual outcomes of vitrectomy for cystoid macular edema due to nonischemic central retinal vein occlusion. Eur J Ophthalmol 2006; 16: 841-6.

[10] Opremcak EM, Rehmar AJ, Ridenour CD, Kurz DE. Radial optic neurotomy for central retinal vein occlusion: 117 consecutive cases. Retina 2006; 26: 297-305.

[11] Jonas JB, Akkoyun I, Kamppeter B, Kreissig I, Degenring RF. Intravitreal triamcinolone acetonide for treatment of central retinal vein occlusion. Eur J Ophthalmol 2005; 15: 751-8.

[12] Ip MS, Gottlieb JL, Kahana A, et al. Intravitreal triamcinolone for the treatment of macular edema associated with central retinal vein occlusion. Arch Ophthalmol 2004; 122: 1131-6.

[13] Gillies MC, Simpson JM, Billson FA, et al. Safety of an intravitreal injection of triamcinolone: results from a randomized clinical trial. Arch Ophthalmol 2004; 122: 336-40.

[14] Jonas JB, Kreissig I, Spandau UH, Harder B. Infectious and noninfectious endophthalmitis after intravitreal high-dosage triamcinolone acetonide. Am J Ophthalmol 2006; 141: 579-80.

[15] Beer PM, Bakri SJ, Singh RJ, Liu W, Peters GB, Miller M. Intraocular concentration and pharmacokinetics of triamcinolone acetonide after a single intravitreal injection. Ophthalmology 2003; 110: 681-6.

[16] Gregori NZ, Rosenfeld PJ, Puliafito CA, et al. One-year safety and efficacy of intravitreal triamcinolone acetonide for the management of macular edema secondary to central retinal vein occlusion. Retina 2006; 26: 889-95.

[17] Cekic O, Chang S, Tseng JJ, et al. Intravitreal triamcinolone injection for treatment of macular edema secondary to branch retinal vein occlusion. Retina 2005; 25 : 851-5.

[18] Williamson TH, O'Donnell A. Intravitreal triamcinolone acetonide for cystoid macular edema in nonischemic central retinal vein occlusion. Am J Ophthalmol 2005; 139: 860-6.

[19] Park SY, Lee SM, Ye SK, Yoon SH, Chung MH, Choi J. Benzo[a]pyrene-induced DNA damage and p53 modulation in human hepatoma HepG2 cells for the identification of potential biomarkers for PAH monitoring and risk assessment. Toxicol Lett 2006; 167: 27-33.

[20] Krepler K, Ergun E, Sacu S, et al. Intravitreal triamcinolone acetonide in patients with macular oedema due to central retinal vein occlusion. Acta Ophthalmol Scand 2005; 83: 71-5.

[21] Krepler K, Ergun E, Sacu S, et al. Intravitreal triamcinolone acetonide in patients with macular oedema due to branch retinal vein occlusion: a pilot study. Acta Ophthalmol Scand 2005; 83: 600-4.

[22] Tewari HK, Sony P, Chawla R, Garg SP, Venkatesh P. Prospective evaluation of intravitreal triamcinolone acetonide injection in macular edema associated with retinal vascular disorders. Eur J Ophthalmol 2005; 15: 619-26.

[23] Park CH, Jaffe GJ, Fekrat S. Intravitreal triamcinolone acetonide in eyes with cystoid macular edema associated with central retinal vein occlusion. Am J Ophthalmol 2003; 136: 419-25.

[24] Yepremyan M, Wertz FD, Tivnan T, Eversman L, Marx JL. Early treatment of cystoid macular edema secondary to branch retinal vein occlusion with intravitreal triamcinolone acetonide. Ophthalmic Surg Lasers Imaging 2005; 36: 30-6.

[25] Chen SD, Sundaram V, Lochhead J, Patel CK. Intravitreal triamcinolone for the treatment of ischemic macular edema associated with branch retinal vein occlusion. Am J Ophthalmol 2006; 141: 876-83.

[26] Antcliff RJ, Spalton DJ, Stanford MR, Graham EM, ffytche TJ, Marshall J. Intravitreal triamcinolone for uveitic cystoid macular edema: an optical coherence tomography study. Ophthalmology 2001; 108: 765-72.

[27] Young S, Larkin G, Branley M, Lightman S. Safety and efficacy of intravitreal triamcinolone for cystoid macular oedema in uveitis. Clin Exp Ophthalmol 200; 29: 2-6.

[28] Jonas JB, Hayler JK, Sofker A, Panda-Jonas S. Intravitreal injection of crystalline cortisone as adjunctive treatment of proliferative diabetic retinopathy. Am J Ophthalmol 200; 13: 468-71.

[29] Martidis A, Duker JS, Greenberg PB, et al. Intravitreal triamcinolone for refractory diabetic macular edema. Ophthalmology 2002; 09: 920-7.

[30] Wingate RJ, Beaumont PE. Intravitreal triamcinolone and elevated intraocular pressure. Aust N Z J Ophthalmol 1999; 27: 431-2. 
[31] Danis RP, Ciulla TA, Pratt LM, Anliker W. Intravitreal triamcinolone acetonide in exudative age-related macular degeneration. Retina 2000; 20: 244-50.

[32] Jonas JB, Sofker A. Intraocular injection of crystalline cortisone as adjunctive treatment of diabetic macular edema. Am J Ophthalmol 2001; 132: 425-7.

[33] Martidis A, Duker JS, Puliafito CA. Intravitreal triamcinolone for refractory cystoid macular edema secondary to birdshot retinochoroidopathy. Arch Ophthalmol 200; 119: 1380-3.

[34] Greenberg PB, Martidis A, Rogers AH, Duker JS, Reichel E. Intravitreal triamcinolone acetonide for macular oedema due to central retinal vein occlusion. Br J Ophthalmol 2002; 86: 247-8.

[35] The Central Vein Occlusion Study Group M report. Evaluation of grid pattern photocoagulation for macular edema in central vein occlusion. Ophthalmology 1995; 102: 1425-33.

[36] Hayreh SS, Hayreh MS. Hemi-central retinal vein occulsion. Pathogenesis, clinical features, natural history. Arch Ophthalmol 1980; 98: 1600-9.

[37] Ip MS, Kumar KS. Intravitreous triamcinolone acetonide as treatment for macular edema from central retinal vein occlusion. Arch Ophthalmol 2002; 120: 1217-9.

[38] Degenring RF, Kamppeter B, Kreissig I, Jonas JB. Morphological and functional changes after intravitreal triamcinolone acetonide for retinal vein occlusion. Acta Ophthalmol Scand 2003; 81: 54850 .

[39] Jonas JB, Kreissig I, Degenring RF. Intravitreal triamcinolone acetonide as treatment of macular edema in central retinal vein occlusion. Graefes Arch Clin Exp Ophthalmol 2002; 240: 782-3.
[40] Bashshur ZF, Ma'luf RN, Allam S, Jurdi FA, Haddad RS, Noureddin BN. Intravitreal triamcinolone for the management of macular edema due to nonischemic central retinal vein occlusion. Arch Ophthalmol 2004; 122: 1137-40.

[41] Chen SD, Lochhead J, Patel CK, Frith P. Intravitreal triamcinolone acetonide for ischaemic macular oedema caused by branch retinal vein occlusion. Br J Ophthalmol 2004; 88: 154-5.

[42] Jonas JB, Akkoyun I, Kamppeter B, Kreissig I, Degenring RF. Branch retinal vein occlusion treated by intravitreal triamcinolone acetonide. Eye 2005; 19: 65-71.

[43] Gillies MC, Simpson JM, Luo W, et al. Randomized clinical trial of a single dose of intravitreal triamcinolone acetonide for neovascular age-related macular degeneration: one-year results. Arch Ophthalmol 2003; 121: 667-73.

[44] Spaide RF, Sorenson J, Maranan L. Combined photodynamic therapy with verteporfin and intravitreal triamcinolone acetonide for choroidal neovascularization. Ophthalmology 2003; 110: 1517-25.

[45] Jonas JB. Intraocular availability of triamcinolone acetonide after intravitreal injection. Am J Ophthalmol 2004; 137: 560-2.

[46] Jaffe GJ, Martin D, Callanan D, Pearson PA, Levy B, Comstock T. Fluocinolone acetonide implant (Retisert) for noninfectious posterior uveitis: thirty-four-week results of a multicenter randomized clinical study. Ophthalmology 2006; 113: 1020-7.

[47] Kuppermann BD, Blumenkranz MS, Haller JA, et al. Randomized controlled study of an intravitreous dexamethasone drug delivery system in patients with persistent macular edema. Arch Ophthalmol 2007; 125: 309-17. 